\title{
1. Introduction: the impending revolution in video technology and its impact on media and regulation
}

Few questions are fraught with more long-term implications than the way we shape our communications system. If the medium is indeed the message, and if these messages influence people and institutions, then today's media technologies will affect media content, and with it future society, culture, and economy.

It is therefore important to understand that we are on the verge of one of humanity's great leaps in media communications, and consequently also of one of its major disruptions of social and economic arrangements. Based on technological and economic trends, change in media will keep speeding up, and help to generate an unprecedented acceleration in the transformation of culture and politics.

These are strong words, but we will substantiate them in this book, and in its companion volume, The Technology, Business, and Economics of Streaming Video. ${ }^{1}$ Both deal with the emerging medium of online video, in its present and future.

Technology is the driver. And with technology progressing exponentially, it is not too early to think about this next generation of television: ever-changing, globalizing, experiential, individualized, immersive, often interactive, and increasingly absorbing attention away from reality. It is not too early to think about its societal impact, public policy issues, and economics. And to ask the question: How will things be progressing over the next years?

This raises the question of whether some of the impending changes are (or might be considered by some to be) negative in nature, and what to do about them. In particular, how to deal with global media market power, a market concentration that is, we will show, inherent to the new medium. Which then leads, inevitably, to governmental countermeasures.

When we look ahead, we conclude that the central players in the next generation of television will be companies we call "video cloud platforms" or simply "video clouds." These are operators that provide the intermediary functions of content providers: content aggregation, marketing, customer relations, advertising placement, and billing, together with the technical distribution functions of storage, content delivery, and technological interoperability. They manage complex data operations and operate next-generation styles of content that are immersive, interactive, and individualized. Increasingly, they also play a role in the production of content itself. We show why such providers will play a dominant role in the emerging media environment, why there will be relatively few of them in number, how they will operate globally, and how societies can deal with them.

1 Noam, Eli. The Technology, Economics, and Business of Streaming Video: The Next Generation of Media Emerges. Cheltenham, UK and Northampton, MA, USA: Edward Elgar Publishing, 2021. 
This is the purpose of this book: to analyze what lies ahead, to raise the understanding of all users of media - which is just about everybody on the planet - to ask how to use and facilitate its positives, and to discuss how to deal with its negatives.

This new-style television is just emerging, with much dynamism around the world. It thus might seem early to think about its impact and its future. But that is also what people said when broadcast TV started with grainy black-and-white pictures, or when cable "community antenna" cable TV carried four or five channels. We can be certain that a next generation of $\mathrm{TV}$ is upon us, and that it will not be simply the same, just more of it.

In the same way that the first two generations of TV were underestimated in their impact, so is the impending new one now. And in the same way that public policy limped behind the past generations of TV as they unfolded, usually restrictive to innovation and supportive of established organizations, so is today's media environment managed by policy-makers who are trying to catch up. Without a long-term vision they let various arrangements emerge haphazardly, and once established, these arrangements are hard to modify or dislodge.

As the culture accelerates, people can adapt to the accelerating environment, or leave it, or change it. Leaving is increasingly unrealistic. Adaptation is the common response. And the third option, creating change, becomes more difficult. The faster we go, the less time we have to think about the way to influence the environment. ${ }^{2}$

We are privileged to live in extraordinary times. Within just a few years, we moved from a communication system that provided us, on an individualized basis, with a mere trickle of information (a few kilobits per second of transmission), to a stream (megabits), and soon to a veritable flood of gigabits of ultra-broadband communications. It is equivalent to stepping up from horses, to trains, to personal automobiles, and to widespread private jets, all within a few years. In the past, we had only very narrow communications pipes available to us individually - telecommunications - and a few bigger pipes that were shared by millions of people watching the same program at the same time - broadcasting. There were only a handful of such "synchronous" broadcast channels. Since then, we have moved to the availability of hundreds of such channels. And we are now moving to an infinity of "asynchronous" content streams because it is unnecessary to share usage with others, except for special live events.

But quantity is only part of the change, and the much easier one to anticipate. The more fundamental change is in the transition of TV from a slow-moving, tightly controlled, standardized technology to one more resembling the dynamics of the internet and information technology (IT). Television has been around since the late 1930s as a consumer medium. In those 80 years, it moved from an analog black-and-white technology to color digital multicasting at a sharper resolution. By our calculation, its bit rate per distribution channel has increased, if one is generous, by a technological compound annual growth rate (CAGR) of about 4 percent per year. In contrast, "Moore's Law" rate - with its doubling for every two years - describes technological change in the IT sector based on advances in the underlying semiconductors, and it comes to about 40 percent a year, ten times as fast.

But now TV is migrating to a distribution over the internet. In the process it is moving away from the control of traditional TV organizations. This has been widely noted. But the attention has been mostly on the level of the widening of content options and providers. This is impor-

2 Haahr, Mads. “The Dreams of an Accelerated Culture." Crossings: eJournal of Art and Technology 1, no. 1 (2001): 1-10. 
tant, of course, but arguably even more fundamental in the long run is the breakdown of the system of substantially uniform TV technology in favor of a system of multiple parallel types of TV. As the video system moves onto the internet and as TV sets become computer-like devices, different technologies can be offered. Competing providers of various technology modules, distribution systems, and content technology will emerge, and their rivalries will transition TV from a system of technical uniformity to one much more resembling that of mobile devices, games, and apps.

As we will discuss, the various technology elements enable a TV content that is a high-resolution, immersive, participatory, individualized, social, mobile, and worldwide experience. Of course, much of the emerging video will continue to be the linear, traditional, classic television of a 22-minute episode program format, surviving in the same way that newspapers, books, and magazines have. But it will decline in its economic and cultural role. The leading edge of creativity, both technologically and culturally, will be in those new media. The kind of television emerging will be partly a "widening": more of everything. But of greater significance is the "deepening": more information, more sensory impressions, more experiential richness. This continues a historic process going back to Gutenberg and beyond.

All this means that media business and media styles will change enormously and need to be thought through. Creative forces in business entrepreneurship and cultural innovation will drive this process that is enabled by technological opportunities. And yet, institutions of business or government cannot adjust at the rate of Moore's Law.

Television, in particular, is caught in the cross-currents of change. It has arguably been the most influential medium for mass culture and politics. It is a major way for people to spend their time. The average American household used to watch about five hours of traditional TV a day. ${ }^{3}$ It is also a huge business and the main vehicle of consumer marketing. Its role and control have been fought over, resulting in a particular regulatory structure. And yet, within a dozen years, one-third of video viewing-time TV has shifted to online. ${ }^{4}$

Today, we are entering the stage where TV programs are delivered over the internet and wireless networks to computers and mobile devices. Media companies are rapidly moving to provide programs, both traditional in style and new ones. With the internet being interactive, new styles and genres of content will emerge that cannot be duplicated by the traditional

3 Average US weekly usage for ascending age groups: 2-11: 24 hours, 16 minutes. 12-17: 20 hours, 41 minutes. 18-24: 22 hours, 27 minutes. 25-34: 27 hours, 36 minutes. 35-49: 33 hours, 40 minutes. 50-64: 43 hours, 56 minutes. 65-plus: 50 hours, 34 minutes. By ethnic groups, African Americans watch an average of 218 hours of television a month; Whites watch 155.3 hours; Hispanics an average of 123.2 hours; and Asian Americans an average of 92.3 hours. Nielsen Research. "Cross-Platform Report." 5 March 2014, https://www.nielsen.com/us/en/insights/report/2014/an-era-of-growth-the-cross-platform -report/\#. United States (US) government figures are lower than Nielsen's, but at 2.8 hours/day still formidable. US Bureau of Labor Statistics. American Time Use Survey Summary, USDL-16-1250, 24 June 2016, www.bls.gov/tus.

4 YouTube started video service in 2005, Netflix in 2007, and Hulu in 2008. In 2017, online viewing in the US per day was already 1 hour and 52 minutes, while traditional TV viewing had declined to 4 hours and 19 minutes. By 2020, online viewing was estimated to be 2 hours and 20 minutes, while regular TV was 4 hours and 4 minutes. Dolliver, Mark. "TV vs. Digital Video. Average Time Spent by Users in the US, 2017-2021.” In “U.S. Time Spent with Media 2019.” eMarketer, 30 May 2019, https://content -na1.emarketer.com/us-time-spent-with-media-2019. 
one-way broadcast medium. And one of the questions around the world is whether the old rules that applied to traditional TV should also apply to the new forms of TV.

For all of these reasons, it is necessary to look ahead, to identify the drivers of change, and in what direction they are taking us. This is not engaging in science fiction. We know what the trends are, what technologies can be used for, what leading-edge adopters are already doing, and what technology companies are offering in hardware and applications. Of course, details of developments are unfathomable in advance, but the broad trend is discernable. There is no need to throw up our hands in despair because only part of the scenario of near-future media can be anticipated. When radio emerged in the 1920s, it was so new and different that it was unpredictable. But the same could not be said for broadcast television and satellite television. For them, one could make strong predictions about where things would be going, based on the experience of the preceding media generation, plus a thoughtful analysis. More recently, the internet was another paradigm shift whose impact was beyond advance analysis. But once established for text, its application to audio and video were much easier to analyze without resorting to wild guesswork. If there was a problem of analysis, it was often the gold rush mentality permeating the environment, which made rational detached analysis difficult.

It has been characteristic of individuals, institutions, industries, and entire societies to misjudge the future. On the one hand, we tend to succumb to the various merchants of hype, overestimating the short-term spread of technology or its salutary impact. On the other hand, we tend to underestimate the long-term impact of fundamental technologies. The automobile and the wireless were seen as convenient substitutes to horseless carriages or telegraph, rather than as the agents of revolutions in cityscape and mass media, of living patterns and politics. It is easy to be smug about the short-sightedness of past generations. But what about our own today? Might we, too, overestimate the short term yet underestimate the long term?

The two books aim to respond to this challenge. Of course, they are not the first on the topic of internet-based media. However, previous volumes often dealt with the entire internet system or with media in general, or they aim to provide skills training for content production. Other books are sociological or cultural and cover the impact of today's social media. A fourth category of books seeks to alert the existing media industry to the impending changes. ${ }^{5}$ This book, and its companion volume, aim to absorb these strands and to cast a wide net - from technology to business to content to regulation - while providing a great deal of specifics since the devil is in the details. In that spirit, this book looks at the next generation of television, with details of the present and a broad perspective on the future. It proceeds as follows:

1. The technologies of content engineering.

2. How these elements, together, lead to different styles of video content.

3. The societal issues accompanying such next-generation TV.

4. The policy implications of such a video system, and how to deal with several of the problems identified.

5. A way to deal with market power and dominance.

5 These books, as well as academic journal articles and other sources, are listed and cited in the various relevant chapters. 
The companion volume to this book, The Technology, Economics, and Business of Streaming, ${ }^{6}$ provides an analysis of related topics:

1. A review of past generations of TV.

2. A review of the new technical elements that are emerging, in both hardware and software.

3. The organizational and technical form of such TV, and the emerging "media clouds."

4. The business models.

5. The fundamental economic characteristics of online TV, and the emerging industry structure.

The volumes complement each other but are free-standing. Neither requires the other. Overlaps occur mostly in the Introduction and Outlook chapters, and in the discussion of the factors for media power (Chapter 5 in this volume, Chapter 6 in the companion volume).

The next generation of TV will have a major impact globally, but perhaps nowhere more than in the US. The US is a major producer of film and TV content to the world (Hollywood). It is also the center of digital technology (Silicon Valley); a center for corporate and startup financing (Wall Street and the venture capital sector); and of advertising (Madison Avenue). Its defense sector conceived space communications and many advances in wireless technology and packet switching. Its university system has set the pace for the internet until recently. And the country's global projection has been based on its "soft power" of its media and culture. Hence, the US media system is near the forefront of this next wave, for economic, technological, and political reasons. Asian countries have prospered with consumer electronics and are now deeply involved in media technology and business; Europe seeks its role in this next convergence of culture and technology, all while protecting human rights; and many other countries resist the inbound flood of content. There is no place or person in this world that will be left untouched by the impending transformation.

We conclude that a small number of cloud platform providers, vertically integrated into content and data, will dominate the system globally. The reasons, as we will see, are the fundamental economics of such operations. Yet it is equally fundamental that the emerging media system must be wide open to voices and competitors.

Thus, we are at the beginnings of a major change in the video field. The implications for many aspects of society will be deep, wide, and long-lasting. This creates a challenge to managers, creatives, and policy-makers in the digital sector. Otherwise, a backlash will produce political forces that will restrict innovation. It is therefore important for academics, public policy analysts, non-governmental organizations, companies, and governments to think creatively about new approaches to these issues, and to balance public interest, technological innovation, media diversity, and infrastructure investments.

The significance of this discussion lies in the fact that most next-generation media applications will run over the internet, loosely defined: music, video, film, interactive games, online news media. As the internet becomes the main platform for most media uses, the regulatory rules for online video become the rules for much of the media system as a whole. And the

6 Noam, Eli. The Content, Impact, and Regulation of Streaming Video: The Next Generation of Media Emerges. Cheltenham, UK and Northampton, MA, USA: Edward Elgar Publishing, 2021.

7 The term "culture," as used throughout this book, refers to the practices, arts and sciences, and social institutions of a society, from their high to their low ends. 
question is whether this form of regulatory treatment will be closer to the print model with its substantial hands-off role for regulation, or closer to the approaches prevalent in broadcasting and telecommunications: that is, substantial regulatory involvement. This is a fundamental question to answer in free societies right at the inception of this media system. Once a basic direction is set, the implementing regulations, business strategies, and investments follow, and soon harden into a status quo that is hard to modify later. Today there is still some fluidity, but the window is closing.

These dynamics will be the subject of this book. 